\title{
Target Value Design: Applications to Newhorn Intensive Care Units
}

Zofia K. Rybkowski, PhD; Mardelle McCuskey Shepley, DArch; and H. Glenn Ballard, PhD

\section{Abstract}

There is a need for greater understanding of the health impact of various design elements in neonatal intensive care units (NICUs) as well as cost-benefit information to make informed decisions about the long-term value of design decisions. This is particularly evident when design teams are considering the transition from open-bay NICUs to single-family-room (SFR) units. This paper introduces the guiding principles behind target value design (TVD) - a price-led design methodology that is gaining acceptance in healthcare facility design within the Lean construction methodology. The paper also discusses the role that set-based design plays in TVD and its application to NICUs.

Key Words: NICU design, hospital design, healthcare facility design, private patient room, target value design, target costing, Lean construction

Author Affiliations: Dr. Rybkowski is Assistant Professor in the Department of Construction Science in the College of Architecture at Texas A\&M University in College Station, TX. Dr. Shepley is a Professor in the Department of Architecture in the College of Architecture and Director, Center for Health Systems and Design, at Texas A\&M University. Dr. Ballard is Adjunct Associate Professor and Research Director for Project Production Systems Laboratory (P2SL) at the University of California, Berkeley.

Corresponding Author: Zofia K. Rybkowski, PhD, Assistant Professor, Department of Construction Science, 434 Langford A, College of Architecture, Texas A\&M University, College Station, TX 77843-3137 (zrybkowski@ tamu.edu; 979-845-4354).

Preferred Citation: Rybkowski, Z. K., Shepley, M. M., \& Ballard, H. G. (2012). Target value design: Applications to newborn intensive care units. Health Environments Research \& Design Journal, 5(4), 5-23.

\section{Introduction}

In light of international and national efforts to provide both optimally designed and economical healthcare environments, a significant effort is underway to address the simultaneous accomplishment of these goals. A sophisticated analysis of the fiscal implications of a proposed healthcare environment is an essential tool for an informed design process.

Although several healthcare projects have employed return on investment (ROI) to justify design decisions, neonatal intensive care units (NICUs) have not been thoroughly addressed. A description of tools for examining the financial impact of design decisions would be helpful to architects and organizations considering new construction. A significant number of new facilities have recently been completed, and a host of others are in the programming and design process. Although there are currently more than 1,000 NICUs in the United States and Canada (American Academy of Pediatrics, 2011), the first NICU was established as recently as 1960 (Gluck, 1985). 


\section{One of the thrusts of EBD has been to examine the ROI of potentially expensive EBD measures.}

Part of the discussion regarding target value design (TVD) has centered on the impact of TVD on design approaches supported by evidence-based design (EBD). According to Hamilton (2006), EBD is "the conscientious and judicious use of current best evidence and its critical interpretation, to make significant design decisions for each unique project. These design decisions should be based on sound hypotheses related to measureable outcomes" (p. 31). One of the thrusts of EBD has been to examine the ROI of potentially expensive EBD measures. Although it is well known that construction costs represent a small portion of a hospital's budget (Berry et al., 2004; Evans, Haryott, Haste, \& Jones, 1998; Kirk $\&$ Dell'Isola, 1995), the impact of new and remodeled construction must be justified.

In the interest of addressing the issue of EBD and ROI in NICUs, this paper describes the TVD process and relevant case studies in healthcare facilities. Additionally, it provides a brief literature review of the construction costs associated with NICUs and recommendations for TVD tools in NICUs that can be used to compare the impact of open versus singlefamily rooms (SFRs).

\section{Evidence-Based Design and Target Value Design}

The recent convergence of two knowledge domains_EBD and Lean construction's TVDhas highlighted the growing importance of developing a more complete picture of the elements that constitute long-term value in NICU facility design. Early EBD indicators suggest that lower capital costs may not necessarily yield the most satisfactory healthcare outcomes long-term. Having a strong understanding of the true financial costs and benefits associated with specific NICU design elements is increasingly important as the implementation of TVD continues to expand.

TVD is a management practice that drives design to deliver customer value and design within project constraints (Ballard, 2011; Denerolle, 2011). TVD emerged from the Lean construction community and its values. Therefore, to understand how and why TVD works requires some understanding of Lean principles.

Lean construction, a project delivery process that seeks to minimize waste and add value, thus inducing flow, has been optimizing the threelegged stool of construction management-time, cost, quality and safety (as the seat) (Jackson, 2004). Value is defined as what customers need to accomplish their purposes. Historically, TVD developed as an adaptation of target costing to construction within the context of Lean construction theory (Rybkowski, 2009); it is "a management practice that seeks to make customer constraints drivers of design for the sake of project delivery." (Ballard, 2011, p. 79). Although the healthcare 
facility owner, architecture, engineering, and construction (OAEC) community is still experimenting with TVD, patterns of a shared methodology have emerged from organizations that have begun implementing it (Ballard, 2011). The following discussion attempts to outline TVD processes generally shared by these early pioneers. A working knowledge of the TVD framework is important for integrating long-term value into a NICU facility.

\section{Lean Construction and the Emergence of Target Value Design}

Success principles that originated from the Toyota Production System, later termed "Lean" production (Liker, 2004; Womack, Jones, \& Roos, 1990), were introduced not only to U.S. manufacturing (Black \& Hunter, 2003; Carreira, 2005; Davis, 2009; Standard \& Davis, 1999), but also to healthcare processing (Arthur, 2011; Graban, 2009; Jimmerson, 2007, 2010; Kenney, 2011; Tapping, Kozlowski, Archbold, \& Sperl, 2009; Zidel, 2006) and construction (Ballard, 2000; Koskela, 1992). Flow is a means to generate value and avoid waste. According to Womack \& Jones (2003), Lean thinking can be condensed into five principles: " $[\mathrm{P}]$ recisely specify value by specific product, identify the value stream for each product, make value flow without interruptions, let the customer pull value from the producer, and pursue perfection" (p. 10).

The Lean ideal toward which processing is pulled might be defined as a state of perfect value-laden flow because it avoids both the waste of work waiting on workers and workers waiting on work. As simple as this task may sound superficially, reaching a state of perfect flow, especially when there are diverse individuals and complex subprocesses involved, is challenging. Although the Lean ideal may never be reached, it can be ever more approximated.

Approaching the Lean ideal of minimum waste and maximum value customarily requires multiple iterations; in Lean parlance, these iterations manifest as kaizen events (continuous improvement) where members of an organization collaborate to plan and run experiments to see whether the recommended changes lead to reduced waste and/or enhanced value. Kaizen events require the participation of numerous individuals because in most organizations the repositories of organizational knowledge are distributed.

This paper discusses the critical importance of deepening understanding of the impact of NICU facility design on patient outcomes, especially as the practice of TVD gains wider acceptance. The authors define TVD as it is practiced now-thus far by Sutter Health (based in California), Unified Health Services (based in Tennessee), SSM Healthcare (based in Missouri), as well as other regions, and spreading to other parts of the United States (Christiansen, 2009; Rybkowski, 2010). They introduce the concept of set-based design and life-cycle cost analysis (two tools fundamental to the TVD process). Finally, a summary of what is known about NICUs and suggestions for how TVD can be applied to improving their design is offered. 


\section{Target Costing and Target Value Design}

Target costing is "a structured approach to determine the life cycle cost at which a proposed product with specified functionality and quality must be produced to generate the desired level of profitability over its life cycle when sold at its anticipated selling price" (Cooper \& Slagmulder, 1997, p. 72). Unlike traditional costing that establishes product price by summing component costs and a profit margin (and thus generates a price that may exceed a customer's willingness or ability to pay), target costing begins with a price the customer is able and willing to pay and subtracts a desired profit margin to reveal the target cost. In other words, target costing is price-led costing, which can be expressed as:

target cost $=$ competitive market price - target profit (Ansari, Bell, \& Group, 1997).

Adopting the target-costing process should not be interpreted as trying to produce a cheap product. In fact, if practiced properly, the process not only eliminates waste, it adds value-as will be discussed shortly in reference to the MacLeamy Curve. The target-costing concept is depicted in Figure 1. Once a viable target cost is established, a core team of OAEC stakeholders is engaged to iteratively redesign the project until the original design cost has been honed to its target cost, as shown in Figure 2. The process requires integrated cross-functional team engagement in value engineering where costs for successive stages of design are continually re-estimated (Clifton et al., 2004).
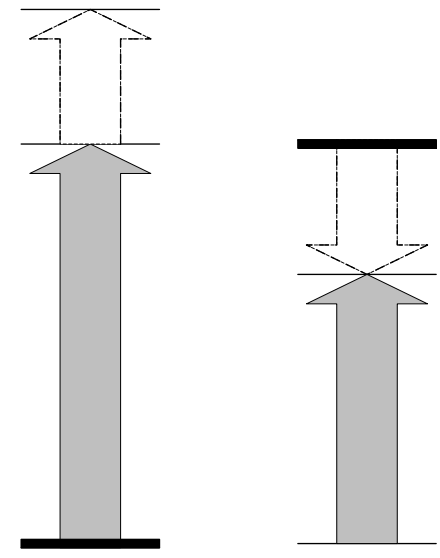

Figure 1. Traditional costing begins with cost (black bar, left) and adds profit markup to determine price. Target costing, by contrast, begins with price (black bar, right) and subtracts profit markup to reveal the target cost at which the product must be produced to meet that price.

Source: Adapted from Rybkowski, 2009, Fig. 46.

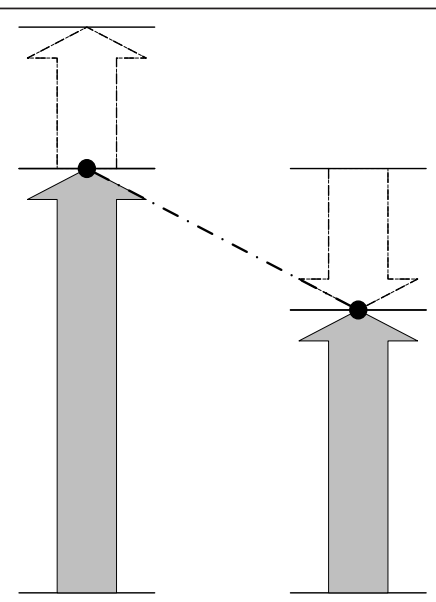

Figure 2. To meet the target cost, multifunctional teams design collectively and continuously, re-estimating the cost as the product's design progresses.

Source: Adapted from Rybkowski, 2009, Fig. 46. 
Table 1. A Comparison of Two Delivery Methods

Carleton College Recreation Center

Completion date
Gross square feet
Project duration
Total cost (including A/E \& CM * fees)
Cost per square foot

April 2000

85,414

24 months

$\$ 13,533,179$

$\$ 158.44$
St. Olaf Fieldhouse

August 2002

114,000

14 months

$\$ 11,716,836$

$\$ 102.79$

${ }^{*} \mathrm{~A}$ (Architecture); E (Engineering); CM (Construction Management)

Note: OAEC stakeholders for the field house at St. Olaf engaged in target-costing exercises as a way to reduce cost and schedule-and enhance value.

Source: Adapted from Ballard \& Reiser, 2004.

Critical to target costing is a cardinal rule: the target cost cannot be exceeded (Clifton, Bird, Albano, \& Townsend, 2004). In other words, if the target cost cannot be met, the project must be cancelled because it will not be economically feasible. OAEC stakeholders must be included in the process of identifying an appropriate target price because the "silo-ization" of OAEC professions has scattered the knowledge base of projects.

A cost-constrained building industry noted the benefits of target-costing, and in 2000 Nicolini and colleagues published one of the first research papers on target costing for the construction industry (Nicolini, Tompkins, Holti, Oldman, \& Smalley, 2000). The authors indicated that target costing had failed, but Ballard and Reiser (2004) later reported success following target costing exercises at the Tostrud Fieldhouse of St. Olaf College in Minnesota. They compared schedule and budget results from the St. Olaf field house with a similar project at Carleton College (Ballard \& Reiser, 2004). The buildings were nonidentical and built in different years and cities, but their functions were similar enough that the differ- ences in construction times and total cost for the two projects are striking (Table 1). As it turned out, the St. Olaf director of facilities reported that Carleton College agreed that Tostrud was also better fit for its purpose.

In 2005, the Project Production Systems Laboratory (P2SL) at the University of California, Berkeley, published a current best practice guide to target costing (Ballard, 2005). The recommended steps included a requirement that all key members of the team (designers, engineers, constructors, and client stakeholders) understand and be involved in the preparation of a feasibility study and subsequent budget - and that the owner be an active and permanent member of the project delivery team, with real tasks to deliver and be accountable for.

In 2005 and 2008, the term target value design formally entered the literature when Macomber and Barberio (2008) used it to refer to target costing in construction. The authors published foundational principles for the process of design, including: concurrently design the product and process in design sets; collaborate in small 
Design decisions made early in the process have the greatest ability to affect cost and

\section{functional capabilities.}

and diverse groups; and meet regularly in a big room. The purpose of working in a big room is to facilitate communication and develop creative synergies. A complete version of their 2008 list is included at the end of this paper.
The now well-publicized MacLeamy Curve demonstrates why early involvement of OAEC stakeholders is critical. Design decisions made early in the process have the greatest ability to affect cost and functional capabilities, as shown in Figure 3. Using a NICU as an example, suppose the architect selects low-emissivity glass for the windows in infant care areas associated with intense solar exposure. If OAEC stakeholders are involved early on, the mechanical engineer will be aware that he or she can downsize the chillers and minimize duct sizes, thus reducing project

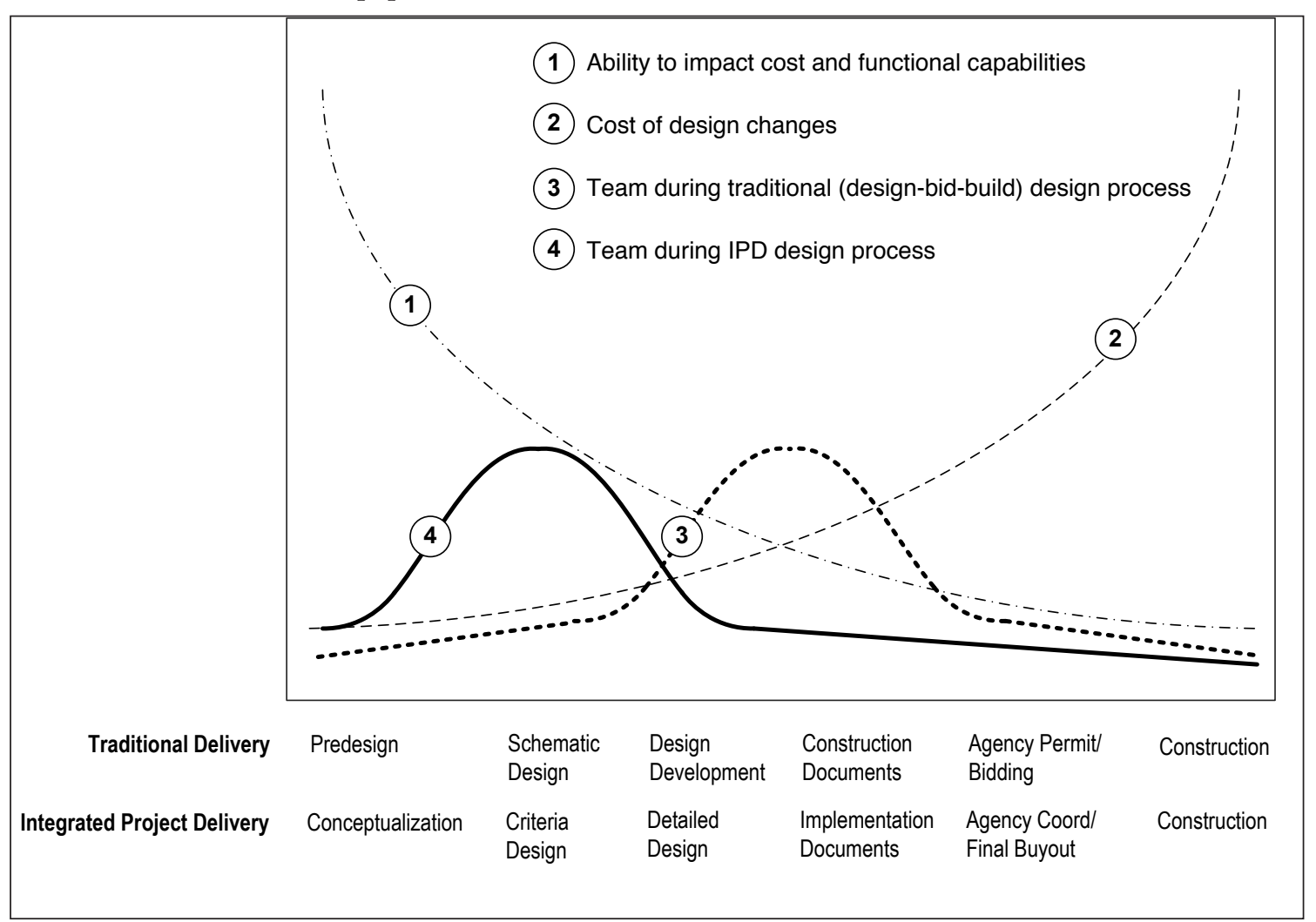

Figure 3. The MacLeamy Curve demonstrates the logic of bringing OAEC members together early in the design process, where the ability to affect cost and function is greatest.

Source: Adapted from MSA, 2004, at http://www.msa-ipd.com/MacleamyCurve.pdf. 
cost. Similarly, once duct sizes are minimized, additional cost savings can be achieved by reducing floor-to-floor heights-if the structural engineer is in the room early on (Barnett, 2004).

By contrast, if a traditional design-bid-build delivery system had been used, many of these cost savings would have been discovered too late in the process to implement them. In addition to the financial benefits implied by the MacLeamy Curve, it is the authors' experience that, unlike TVD, traditional design-bid-build systems pit architectural, engineering, and construction (AEC) service providers against the owner because owner aspirations have been both generated without an understanding of what the owner can actually afford, and financial risk has been contractually pushed downward from the owner through the AEC stakeholder team. The result is both an adversarial system of relationships of agreement contract creates an environment where risk is shared among OAEC stakeholders and provides pain-sharing (above allowable cost) and gain-sharing (below allowable cost) incentives to motivate the team to collectively reach both allowable cost and target cost goals (Lichtig, 2005a, 2005b, 2006).

Thus far, experimentation with TVD on healthcare facility projects has yielded the preliminary results shown in Table 2. Tabulation of these results shows that the average cost savings during a TVD exercise reach nearly $13 \%$. Because TVD experimentation is in its early days, some practitioners believe that much greater savings are possible.

\section{Set-Based Design}

Set-based design is integral to TVD and may be likened to setting a meeting appointment time and last-minute cost cutting severed from the project as a whole, resulting in compromise in design and construction quality.

By contrast, with TVD providers and suppliers help the owner early on to establish an informed allowable cost (the make-or-break cost goal critical for a project to be economically feasible) and target cost (a "stretch" goal that would be desirable, though not critical, to reach), as shown in Figure 4. If there is a substantial gap between the market cost and the allowable cost, TVD spurs the creation of innovative solutions. An integrated form

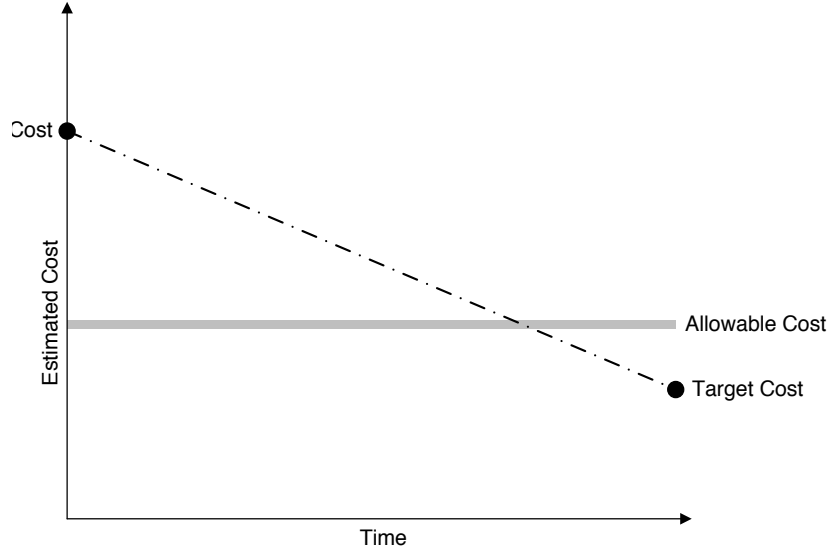

Figure 4. The target-costing goal diagram (time versus cost) used by Sutter Health during its target-costing exercises for the CPMC Cathedral Hill Hospital in San Francisco, CA.

Source: Adapted from Rybkowski, 2009 
Table 2. Summary of Results From TVD Exercises Completed to Date

\begin{tabular}{|c|c|c|c|c|c|}
\hline $\begin{array}{c}\text { Project Size } \\
\text { (sf) }\end{array}$ & $\begin{array}{c}\begin{array}{c}\text { Year } \\
\text { of } \\
\text { Completion }\end{array} \\
\end{array}$ & Market Cost & Actual Cost & $\begin{array}{c}\text { Cost } \\
\text { Reduction } \\
\text { (\%) }\end{array}$ & \\
\hline 368,882 & 2009 & $\$ 98,000,000$ & $\$ 89,200,000$ & 9.0 & \\
\hline 230,000 & 2007 & $\$ 22,000,000$ & $\$ 17,900,000$ & 18.6 & \\
\hline 114,000 & 2002 & $\$ 13,533,179$ & $\$ 11,717,000$ & 13.4 & \\
\hline 75,362 & 2006 & $\$ 13,600,000$ & $\$ 11,200,000$ & 17.6 & \\
\hline \multirow[t]{2}{*}{30,000} & 2010 & $\$ 14,500,000$ & $\$ 13,700,000$ & 5.5 & \\
\hline & & & & 12.8 & $\begin{array}{l}\text { Average \% Cost } \\
\text { reduction }\end{array}$ \\
\hline
\end{tabular}

with a group of parties via e-mail. If, for example, Tuesday at 10:00 a.m. is the only time the meeting organizer proposes, the e-mail must travel through multiple parties — back and forth — until a satisfactory time is reached; this is a potentially lengthy process. NICU staff members have intense and complex schedules and coordinating meeting times is challenging. In a set-based approach, by contrast, a meeting organizer proposes a range of possible times using a meeting software program, allowing for the much faster identification of intersecting time slots available for all parties (Parrish, 2009; Parrish et al., 2007).

Similarly, set-based design exercises challenge a group to simultaneously identify multiple alternatives to achieve the same functionality (Cooper \& Slagmulder, 1997). As OAEC stakeholder groups successively evaluate each alternative according to whether the alternative can accommodate specific constraints, the list of design options narrows. In the case of a NICU design process, the cluster might include a nurse, a doctor, a family member, and an administrator. Ward, Liker, Cristiano, and Sobek II (1995) contrast the set-based design approach with point-based design, where one alternative is modified through the contribution of various relevant stakeholders. The problem with point-based design is that one alternative must be modified through multiple iterations, and designers of segments are often working both sequentially and in isolation (called "throw it over the wall" approach); once the alternative reaches a "hard" constraint (i.e., a code violation or impassable owner requirement) upon evaluation by a later stakeholder, all earlier iterations performed on that alternative may be classified as waste.

Whereas point-based design is a linear, throw-it-over-the-wall type of process, set-based design involves funneling. 


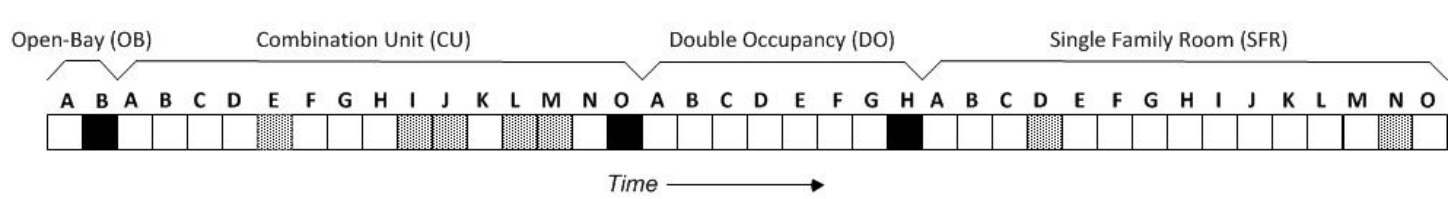

A, B... Requirement that design must meet
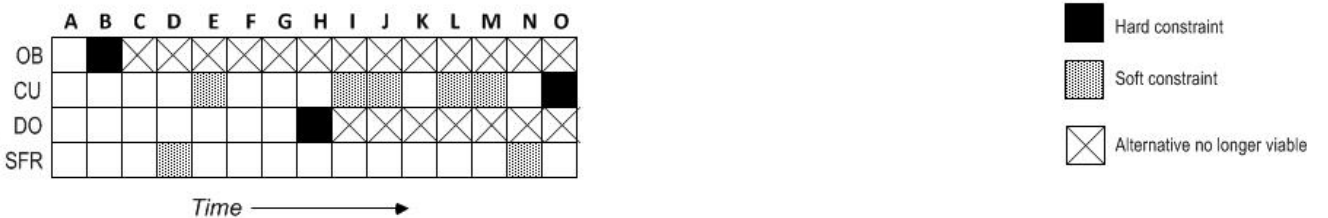

Figure 5. During a traditional "throw-it-over-the-wall" point-based design approach (top), OAEC members consider each NICU configuration separately and sequentially in time. By contrast, during a "funneling" set-based design approach (bottom), a set of NICU configuration alternatives is considered, and alternatives are simultaneously assessed and revised or eliminated, greatly reducing the time it takes for the OAEC team to rework designs at points of constraint—and to reach a final consensus.

A comparable situation in the design of a NICU would be to have the physicians and others meet in separate groups. Whereas pointbased design is a linear, throw-it-over-the-wall type of process, set-based design involves funneling. The set of viable alternatives narrows increasingly as alternatives are simultaneously evaluated and successively eliminated by a core set of OAEC stakeholders. The example shown in Figure 5 represents one project team's evaluation of four NICU configurations. Note that a different OAEC project team might evaluate the configurations differently from the one shown, subjecting them to its own code and owner constraints.

When a project team is co-located, as was practiced during the design of Sutter Health's CPMC Cathedral Hill Hospital, each design idea is documented individually on A3-sized paper (similar to the $11 " \times 17 "$ standard cut) and posted publically on the wall of the design office for consideration by the full OAEC team. These ideas are evaluated concurrently. If life-cycle cost or ROI analysis as performed by engineers is used (ASTM, 2006; Bull, 1993; Kirk \& Dell'Isola, 1995; Langston, 2005), practioners should take care to implement incremental analysis when comparing alternatives. The Cathedral Hill project instead implemented a process called "Choosing by Advantages" (Suhr, 1999) to evaluate and winnow alternatives - a decision-making methodology designed to develop consensus among stakeholders with different interests and criteria.

\section{Target Value Design and Set-Based Design Issues in NICUs}

A recent trend in employing ROI analyses is to study the impact of EBD features on long-term 
staff and maintenance costs. A variation on this theme is to compare different approaches to particular design issues. In the case of neonatal intensive care, several recurring topics confront designers. These controversies include unit location in the context of the hospital, degree of homelike-ness, the number of babies per unit, supply location (centralized versus satellite versus bedside), access to nature, and the number of patients per room. Currently, the subject most frequently debated is the number of patients per room, specifically whether a unit should provide private family rooms, open bays, combined units, or shared rooms.

Private rooms, commonly called single-family rooms (SFRs), typically accommodate family space within the room and should be at least 160 net square feet (nsf), according to the New Recommended Standards for NICU Design (White, Smith, \& Harrell, 2012). In a survey of 11 NICUs of varying room densities, the average private room was found to be 172 nsf (Harris, Shepley, White, Kolberg, \& Har-

\section{The issue of shared versus} private rooms and associated hybrids in NICUs has probably been the most frequently discussed issue in NICU design.

roll, 2006). An open-bay NICU varies in the amount of space allocated to a child, although the minimum established by the Recommended Standards is 120 nsf per infant (White et al., 2007). Configurations for these spaces are shown in Figure 6.

The issue of shared versus private rooms and associated hybrids in NICUs has probably been the most frequently discussed issue in NICU design. Most studies suggest that private rooms are beneficial for staff, infants, and families (Carter, Carter, \& Bennett, 2008; Ortenstrand, Westrup, \& Brostrom, 2010; Rosenblum, 2005; Shepley, Harris, \& White, 2008; Shepley, Harris, White,
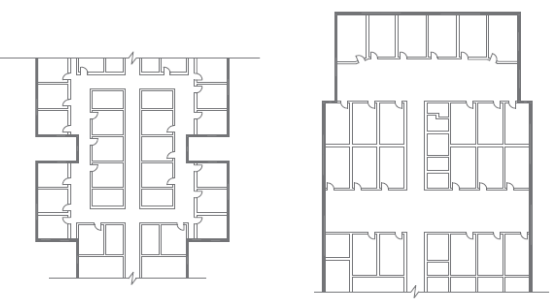

Single-Family Room

Double-Occupancy

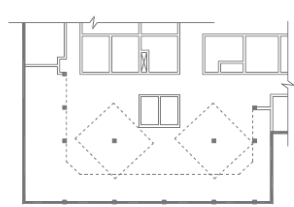

Open-Bay

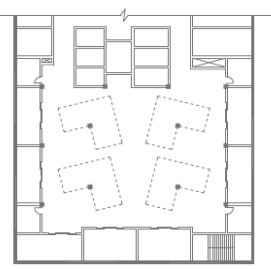

Combination Unit

Figure 6. In set-based design, typical NICU configuration floor plans should be evaluated simultaneously as a set. 
\& Steinberg, 2008; Smith, Schoenbeck, \& Clayton, 2009; Stevens, Helseth, Khan, Munson, \& Reid, 2011; Walsh, McCullough, \& White, 2006); however, some of these SFR studies do not support all outcomes (White, 2011). "Although families appreciate the increased privacy and ownership they feel in a private room, they can also feel somewhat isolated. Caregivers likewise can feel isolated from their colleagues, especially if a central gathering area is not provided" (White, 2011, p. 5).

\section{The Importance of Cost Research Regarding the Implications of SFRs}

NICU operations play a significant role in the financial operation of a hospital. According to National Vital Statistics Reports, $12.18 \%$ of births in 2009 were premature (Martin et al., 2011). The annual hospitalization cost for these infants was $\$ 51,600$ per infant (Institute of Medicine, 2006). Phillips notes that high-risk newborn care is the most profitable component of obstetric practice and cites an estimated $7 \%$ increase in NICU population between 2007 and 2015 (Phillips, 2010).

These strong NICU volume trends offer a significant contribution profit opportunity for hospitals offering neonatology services.... As VCM (variable contribution to margin) increases, hospitals can more easily underwrite the fixed cost associated with OB (obstetrics). Therefore NICUs offer hospitals and health care organizations tremendous profit opportunity. (Phillips, 2010, p. 4)

\section{Previous Studies on the Cost Implications of Private Rooms}

Most of the discussion around the pros and cons of private versus shared rooms has centered on the adult population. Chaudhury et al. provide a thorough summary of the literature on this topic, including a meta-analysis of cost information that suggests that operating costs drop, capital costs rise, occupancy rates increase, length of stay decreases, and medication errors and costs diminish in private rooms (Chaudhury, Mahmood, \& Valente, 2005).

According to Boardman and Forbes (2007), private rooms are more desirable to adult patients, they support recovery time, they require more space, and they are more expensive to construct and operate than shared rooms. In their study of the cost-benefit analysis of the two options, they found the increase in cost (land, construction, maintenance, and staffing) for each private room to be $\$ 228,000$ (Canadian) based on the present value of a 50-year life span and a discount rate of $3.5 \%$. Considering the health and social benefits (willingness to pay, patient transfers, reduced waiting time) of the private room, the difference is approximately $\$ 70,000$ (Canadian) (Boardman \& Forbes, 2007). The difference in construction cost alone is believed to be approximately $\$ 61,000$, assuming the shared room is $287 \mathrm{nsf}$ per person and the private room is 436 nsf (Boardman \& Forbes, 2007).

A simple (undiscounted) payback and a discounted (3.5\%) payback cost tally of Boardman and Forbes' (2007) data for private 
Table 3. Comparison of First (Capital) and Long-Term Costs for Semi-Private and Private Adult Patient Rooms-as well as Forecasted Simple and Discounted Payback Periods, Should Private Rooms Be Selected Over Semi-Private Rooms

\begin{tabular}{|c|c|c|c|c|c|}
\hline Alternative & First Cost & Annual & lows & $\begin{array}{c}\text { Simple } \\
\text { (Undiscounted) } \\
\text { Payback Period }\end{array}$ & $\begin{array}{c}\text { Discounted } \\
(3.5 \%) \\
\text { Payback Period }\end{array}$ \\
\hline & & Benefit & Cost & & \\
\hline I (Semi-private) & \multicolumn{4}{|c|}{17,290} & \\
\hline II (Private) & $-207,395$ & $\begin{array}{r}+35,303 \\
2 \\
\end{array}$ & $-8,468$ & & \\
\hline$\Delta$ & $-70,876$ & \multicolumn{2}{|c|}{$\begin{array}{c}26,835 \\
9,545\end{array}$} & Approx. 7.4 years & 8.75 years \\
\hline
\end{tabular}

Source: Adapted from Boardman \& Forbes (2007).

rooms for adult populations suggest that more expensive private rooms pay for themselves after 7.4 years, and 8.75 years, respectively, as shown in Table 3. Any savings garnered after the payback period is a long-term financial benefit for the owner.

In general, authors have suggested that private room construction for adults is more expensive than shared rooms and open bays (Calkins \& Cassella, 2007; Moon, 2005), although the operational costs due to flexibility of patient location are believed to recoup the additional construction cost within a few years (Calkins \& Cassella, 2007).

\section{Previous Studies on the Cost Implications of NICUs}

To the authors' knowledge, there is only one study on the cost implications of SFRs, and only a handful of studies that address construction costs in NICUs generally. Regarding the overall NICU, journal publications include:

- Berens and Weigle examined the impact of

Table 4. Costs for Renovation of a NICU Room

\begin{tabular}{lccc} 
Item & 1997 Labor \& Materials & 2011 Labor \& Materials* \\
\hline Weather stripping on cupboards \& drawers & $\$ 200$ & $\$ 280$ \\
\hline Change trash cans & $\$$ & 40 & $\$ 56$ \\
\hline Carpeting & $\$ 715$ & $\$ 1,002$ \\
\hline Incubator covers & $\$ 550$ & $\$ 771$ \\
\hline Acoustical tile & $\$ 2,500$ & $\$ 3,504$ \\
\hline Individually controlled lighting & $\$ 3,200$ & $\$ 4,485$ \\
\hline Total & $\$ 7,205$ & $\$ 10,098$ \\
\hline
\end{tabular}

*Adjusted to 2011 per U.S. Department of Labor http://www.bls.gov/data/inflation_calculator.htm Source: Walsh-Sukys et al., 2001) adjusted to 2011. 


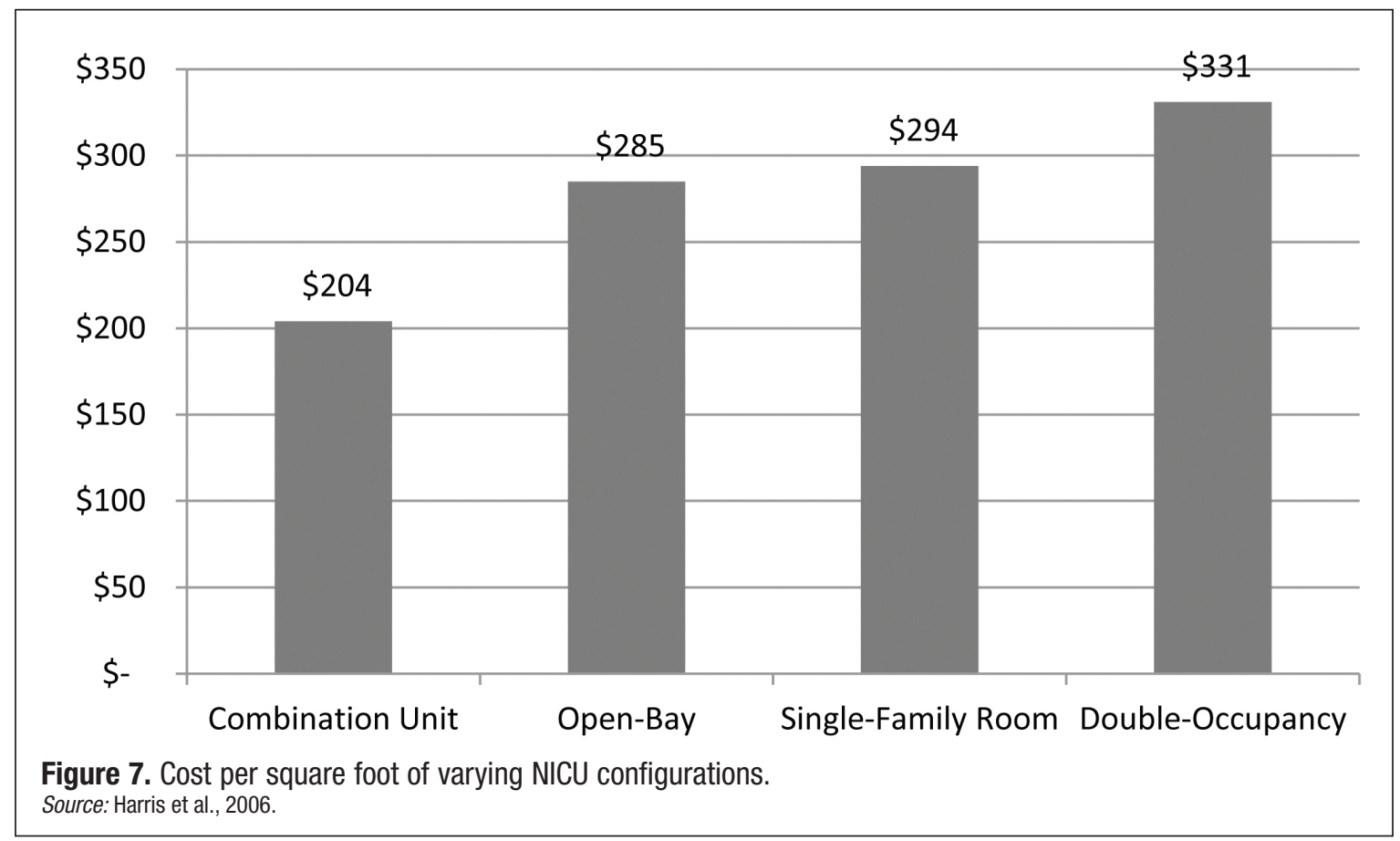

acoustical ceiling tile replacement in an open bay NICU (cost approximately $\$ 2,400$ ), and found a decibel reduction level from 55 to 53 $(p<0.05)$ (Berens \& Weigle, 1996).

- Medical physician Robert White discusses the relative costs of flooring materials in the context of safety, economy, environmental impact, durability, comfort, sound control, and acoustics (White, 2007).

- Walsh-Sukys and colleagues modified an existing NICU six-patient room to enhance the acoustical and lighting environment and were able to reduce noise and light levels and increase staff satisfaction relative to a control room at a 1997 cost of approximately $\$ 7,200$ (Walsh-Sukys, Reitenbach, Hudson-Barr, \& DePompei, 2001). These amounts are tabulated in Table 4.
With specific regard to construction costs associated with open-bay units versus SFRs, Harris et al. (2006) gathered data from 11 hospitals built between 1995 and 2005. The results are summarized in Figure 7; they suggest that combination units are the least expensive, followed by openbay, SFR, and double-occupancy units (Harris et al., 2006).

As part of the same study, the researchers found that the average area per infant station was lowest in a double-occupancy unit (340 nsf/infant), followed closely by the combination unit (370 nsf/infant). The open-bay units averaged 468 nsf/infant, and the average for the SFRs was 692 nsf/infant (Harris et al., 2006). According to Harris and colleagues (2006) the average area 
Deciding whether to build an

SFR versus open-bay NICU can be addressed using target value design set-based design analysis.

dedicated to an infant in an open NICU was $107 \mathrm{nsf}$, whereas the average area in an SFR was 172 nsf.

\section{Target Value Design and Single-Family- Room versus Open-Bay NICUs}

"A wise planner will balance innovation and effectiveness." (Harrell \& Moon, 2008, p. 48)
Deciding whether to build an SFR versus open-bay NICU can be addressed using TVD set-based design analysis. In a traditional linear delivery system, the owner and designers might specify the type of NICU configuration they are most familiar with and then successively iterate it until they reach a configuration they find most appropriate for their needs. In set-based design, by contrast, the OAEC will generate multiple design alternatives simultaneously (e.g., open-bay, double rooms, SFRs, or combination units) and then evaluate the merits of each alternative simultaneously, making adjustments for owner priorities. A rough scoring model might be developed for a NICU, as shown in Table 5. (Because an explanation of the Choosing by Advantages system implemented by Sutter Health is beyond the scope

Table 5. Example of Scoring Model Showing NICU Design Alternatives, Rated From 1- 5 (Least to Most Effective) for Each Desired Criteria

Owner

\begin{tabular}{cr|cc|cc|cc|cc} 
Priorities & & \multicolumn{1}{c}{ CU } & OB & SFR & DO \\
\hline 0.15 & Appropriate acoustics & 3 & 0.45 & 1 & 0.15 & 5 & 0.75 & 4 & 0.60 \\
0.15 & Appropriate lighting & 3 & 0.45 & 2 & 0.30 & 5 & 0.75 & 4 & 0.60 \\
0.10 & Flexibility & 4 & 0.40 & 3 & 0.30 & 3 & 0.30 & 2 & 0.20 \\
0.35 & Privacy for families & 3 & 1.05 & 1 & 0.35 & 5 & 1.75 & 3 & 1.05 \\
0.25 & Staff interaction & 3 & 0.75 & 5 & 1.25 & 2 & 0.50 & 3 & 0.75 \\
\hline 1.00 & & 3.1 & & 2.35 & & 4.05 & & 3.2
\end{tabular}

$\begin{array}{cl}\text { CU } & \text { Combination unit } \\ \text { OB } & \text { Open-bay } \\ \text { SFR } & \text { Single-family room } \\ \text { DO } & \text { Double-occupancy }\end{array}$

Note: Criteria are weighted by percentage (totaling 1) in alignment with a specific owner's priorities and will vary by owner. 
of this paper, the reader is advised to separately consult Suhr [1999] to understand the consensusbuilding decision-making process it employs - a methodology some consider superior to a scoring model.)

A NICU design team wishing to undertake TVD might follow the steps outlined in Figure 8. Note that each step in the process requires integrated collaboration among OAEC team members. There are also nodes to contemplate cancellation if it is discovered the project cannot be constructed at or below the allowable cost.

In addition to the mechanics of TVD, it should be remembered that the TVD process is accomplished within the integrated project delivery format of Lean. The Lean culture is one of collaboration, trust, shared decision making, reliable promises, and risk sharing (Lichtig, 2006). For designers of NICUs as well as other professionals, there are at least nine foundational practices key to a successful TVD process. Based on the general categories of Macomber and Barberio (2008) and customized for the NICU application, they are:

1. Engage deeply with the hospital-based NICU team members (e.g., medical staff, administrators, families) to establish the target value.

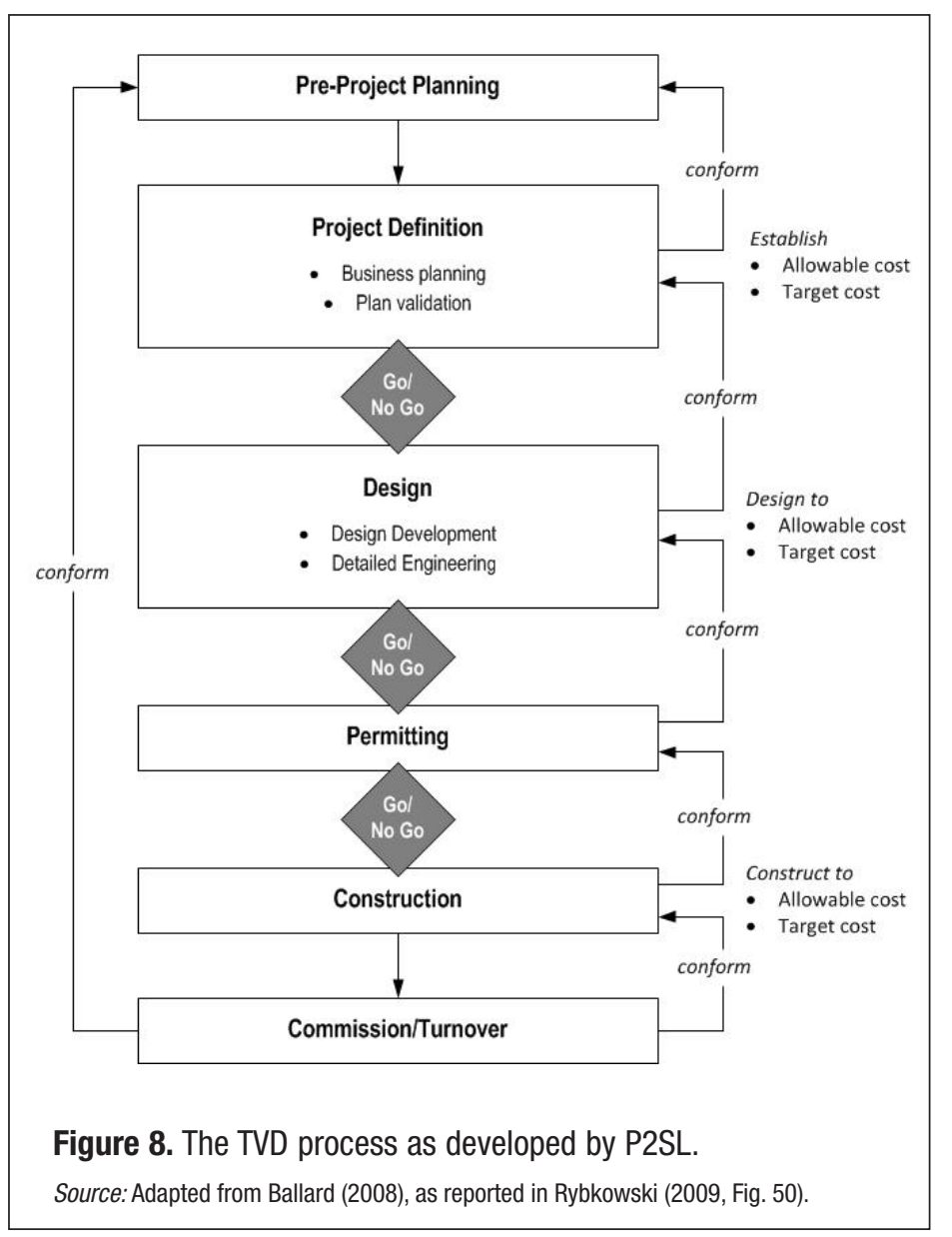

2. Lead the design effort for learning and innovation.

3. Design to a detailed estimate.

4. Collaboratively plan and replan the project.

5. Concurrently design the project and the process in design sets.

6. Design and detail in the sequence in which NICU staff, families, and patients will use the spaces.

7. Work in small and diverse groups representing neonatologists and other medical staff, developmental care teams, administrators, and cur- 
rent and previous NICU families - as well as representatives from the design, engineering, and construction stakeholder organizations.

8. Work in a "big room" (ideally, a dedicated space near the existing NICU to facilitate user participation).

9. Conduct retrospective presentations throughout the process to ensure learning and continuous improvement.

These practices are described in greater detail in the TVD literature (Ballard, 2005; Ballard, 2011; Ballard \& Morris, 2010; Denerolle, 2011; Macomber \& Barberio, 2008; Rybkowski, 2009). Any project team interested in undertaking a TVD exercise would be wise to study well the tools and culture that are inherent to success.

\section{Conclusion}

One purpose of this paper was to give NICU owners and stakeholders a structured understanding of the NICU design process within the practice of TVD so they are better prepared to implement this new process as the practice of TVD spreads. Calculating capital cost per square foot is the first step necessary to evaluate set-based design alternatives for NICUs. However, it is critical to know the long-term costs and benefits associated with each NICU configuration to confidently select the option that delivers maximum longterm value for the customer. TVD is an effective means of allowing NICU design teams to understand the relative merits and cost implications of potential design alternatives.

\section{References}

American Academy of Pediatrics. (2011). Newborn intensive care units (NICUs) and neonatologists of the USA \& Canada. Rockville, MD: Neonatology Today.

Ansari, S., Bell, J., \& CAM-I Target Cost Core Group. (1997). Target costing: The next frontier in strategic cost management. Austin, TX: Consortium for Advanced Manufacturing International.

Arthur, J. (2011). Lean six sigma for hospitals: Simple steps to fast, affordable, flawless healthcare. New York, NY: McGraw-Hill.

ASTM. (2006). Standard practice for measuring life-cycle costs of buildings and building systems. Annual Book of ASTM Standards. West Conshohocken, PA: Author.

Ballard, H. G. (2000). The last planner system of production control. Doctorate, University of Birmington, United Kingdom.

Ballard, G. (2005).P2SL report: Current benchmark in target costing. Retrieved from http://p2sl.berkeley.edu/2009-05-26/P2SL\%20 Report\%20on\%20the\%20Current\%20Benchmark\%20in\%20 Target\%20Costing\%202005-11-28.pdf

Ballard, G. (2011). Target value design: Current benchmark (1.0). Lean Construction Journal, 79-84

Ballard, G., \& Reiser, P. (2004). The St.Olaf College fieldhouse project: $A$ case study in designing to target cost. Paper presented at the Proceedings of the 12th Annual Conference of the International Group for Lean Construction (IGLC-12), August 3-5, 2004, Elsinore, Denmark.

Ballard, H. G., \& Morris, P. H. (2010). Maximizing owner value through target value design. AACE International Transactions, 1(1). Retrieved from http://connection.ebscohost.com/c/articles/52475948/maximizing-owner-value-through-target-valuedesign

Barnett, D. L. (2004). A primer on sustainable building. Snowmass, CO: Rocky Mountain Institute.

Berens, R., \& Weigle, C. (1996). Cost analysis of ceiling tile replacement for noise abatement. Journal of Perinatology, 16(3), 199-201.

Berry, L. L., Parker, D., Coile, R. C., Hamilton, D. K., O’Neille, D. D., \& Sadler, B. L. (2004). The business case for better buildings. Frontiers of Health Services Management, 21(1), 5-24.

Black, J. T., \& Hunter, S. L. (2003). Lean manufacturing systems and cell design. Dearborn, MI: SME.

Boardman, A., \& Forbes, D. (2007). A cost-benefit analysis of private versus semi-private inpatient rooms in a new hospital. Working paper. Phelps Centre for the Study of Government and Business, Sauder School of Business, Vancouver, BC.

Bull, J. W. (1993). Life cycle costing for construction. London, United Kingdom: Blackie Academic \& Professional.

Calkins, M., \& Cassella, C. (2007). Exploring the cost and value of private versus shared bedrooms in nursing homes. Gerontologist, 47(2), 169-183.

Carreira, B. (2005). Lean manufacturing that works: Powerful tools for dramatically reducing waste and maximizing profits. New York, NY: AMACOM. 
Carter, B., Carter, A., \& Bennett, S. (2008). Families' views upon experiencing change in the neonatal intensive care unit environment from the "baby barn" to the private room. Journal of Perinatology, 28, 827-829.

Chaudhury, H., Mahmood, A., \& Valente, M. (2005). Advantages and disadvantages of single versus multiple occupancy rooms in acute care environments: A review and analysis of the literature. Environment \& Behavior, 37(6), 760-786.

Christiansen, C. (2009). Embracing change. Health Environments Research \& Design Journal, 3(1), 15-27.

Clifton, M. B., Bird, H. M. B., Albano, R. E., \& Townsend, W. P. (2004). Target costing: Market-driven product design. New York, NY: Dekker.

Cooper, R., \& Slagmulder, R. (1997). Target costing and value engineering. Portland, OR: Productivity Press.

Davis, J. W. (2009). Lean manufacturing: Implementation strategies that work. New York, NY: Industrial Press.

Denerolle, S. (2011). Technical report: The application of Target value design to 3 hospital projects. Project Production Systems Laboratory, University of California, Berkeley.

Evans, R., Haryott, R., Haste, N., \& Jones, A. (1998). The long term costs of owning and using buildings. London, UK: Royal Academy of Engineering.

Gluck, L. (1985). Conceptualization and initiation of a neonatal intensive care nursery in 1960. Paper presented at the Neonatal Intensive Care: A History of Excellence, October 7 Bethesda, MD.

Graban, M. (2009). Lean hospitals: Improving quality, patient safety, and employee satisfaction. Boca Raton, FL: CRC Press.

Hamilton, D. K. (2006). Evidence-based design supports evidencebased medicine in the ICU. ICU Management Journal (Belgium), $6(3), 31$.

Harrell, J., \& Moon, R. (2008). Designs for the delicate. Health Facilities Management, 21(12), 45-48.

Harris, D., Shepley, M., White, R., Kolberg, J., \& Harroll, K. (2006) The impact of single family room design on patients and caregivers: Executive summary. Journal of Perinatology, 26(Suppl 3), S38-S48.

Institute of Medicine. (2006). Preterm birth: Causes, consequences, and prevention. Washington, DC: National Academy of Sciences.

Jackson, B. (2004). Construction management jump start. Indianapolis, IN: Wiley.

Jimmerson, C. (2007). A3 problem solving for healthcare: A practical method for eliminating waste. Boca Raton, FL: CRC Press.

Jimmerson, C. (2010). Value stream mapping for healthcare made easy. Boca Raton, FL: CRC Press.

Kenney, C. (2011). Value stream mapping for healthcare made easy. Boca Raton, FL: CRC Press.

Kirk, S. J., \& Dell'Isola, A. J. (1995). Life cycle costing for design professionals. New York, NY: McGraw-Hill.
Koskela, L. (1992). Application of the new production philosophy to construction. In CIFE Technical Report \#72 (pp. 1-81). Stanford, CA: Stanford University.

Langston, C. A. (2005). Life-cycle cost approach to building evaluation. Amsterdam, The Netherlands: Elsevier.

Lichtig, W. A. (2005a). Sutter Health: Developing a contracting model to support Lean project delivery. Lean Construction Journal, 2(1), 105-112.

Lichtig, W. A. (2005b). Ten key decisions to a successful construction project: Choosing something new - the Integrated Agreement for Lean Project Delivery. September 29-30, The Intercontinental Toronto Centre.

Lichtig, W. A. (2006). The integrated agreement for Lean project delivery. Construction Lawyer, 26(3), 1-8.

Liker, J. (2004). The Toyota way. New York, NY: McGraw-Hill.

Macomber, H., \& Barberio, J. (2008). Target value design: Nine foundational practices for delivering surprising client value. Retrieved from http://www.leanproject.com/wp-content/ uploads/2011/10/3-Target-Value-Design-LPC.pdf

Martin, J. A., Hamilton, B. E., Ventura, S. J., Osterman, M. J., Kirmeyer, S., Mathews, T. J., ... Wilson, E. C. (2011). Births: Final data for 2009. In N. V. Statistics (Ed.), National Vital Statistics Reports (Vol. 60, No. 1). Hyattsville, MD: National Center for Health Statistics.

Moon, S. (2005). Construction and costs-Going up. Modern Healthcare, 35(10), 30-42.

Nicolini, D., Tompkins, C., Holti, R., Oldman, A., \& Smalley, M. (2000). Can target costing and whole life costing be applied in the construction industry? Evidence from two case studies. British Journal of Management, 11, 303-324.

Ortenstrand, A., Westrup, B., \& Brostrom, E. A. (2010). The Stockholm neonatal family centered care study: Effects of length of stay and infant morbidity. Pediatrics, 125, e278-e285.

Parrish, K. (2009). Applying a set-based design approach to reinforcing steel design. Doctoral dissertation, University of California, Berkeley, Berkeley, CA.

Parrish, K., Stransky, K. E., Rogers, C., Duncan, M. H., Smith, G. C., Neil, J., ... Inder, T. (2007). Exploration of set-based design for reinforced concrete structures. Paper presented at the International Group for Lean Construction (IGLC-15), MI, 213-222.

Phillips, C. R. (2010). Family-Centered Maternity Care Business Case. Santa Cruz, CA: Phillips + Fenwick.

Rosenblum, D. (2005). Single family room care: Before and after data. Paper presented at the Gravens Conference: The Physica and Developmental Environment of the High-Risk Infant, January 26-28, Clearwater Beach, FL..

Rybkowski, Z. (2009). The application of root cause analysis and target value design to evidence-based design in the capital planning of health care facilities. Doctoral dissertation, University of California, Berkeley, Berkeley, CA.

Rybkowski, Z. K. (2010). Letter to the editors. Health Environments Research \& Design Journal, 3(2), 126-130.

Shepley, M., Harris, D., \& White, R. (2008). Open-bay and single family room neonatal intensive care units: Caregiver satisfaction and stress. Environment \& Behavior, 40(2), 249-268. 
Shepley, M., Harris, D., White, R., \& Steinberg, F. (2008). Impact of single-family rooms on family behavior. The AIA Report on University Research, 3, 174-185.

Smith, T. J., Schoenbeck, K., \& Clayton, S. (2009). Staff perceptions of work quality of a neonatal intensive care unit before and after transition from an open bay to a private room design. Work, 33, 211-227.

Standard, C., \& Davis, D. K. (1999). Running today's factory: $A$ proven strategy for lean manufacturing. Cincinnati, $\mathrm{OH}$ : Hanser Gardner Publications.

Stevens, D. C., Helseth, C. C., Khan, M. A., Munson, D. P., \& Reid, E. J. (2011). A comparison of parent satisfaction in an open-bay and single-family room neonatal intensive care unit. Health Environments Research \& Design Journal, 4(3), 110-123.

Suhr, J. (1999). The choosing by advantages decisionmaking system. Westport, CT: Quorum Books.

Tapping, D., Kozlowski, S., Archbold, L., \& Sperl, T. (2009). Value stream management for Lean healthcare: Four steps to planning, mapping, implementing and controlling improvements in all types of healthcare environments. Chelsea, MI: MCS Media Inc.

Walsh, W. F., McCullough, K. L., \& White, R. D. (2006). Room for improvement: Nurses' perceptions of providing care in a single room newborn intensive care setting. Advances in Neonatal Care, 6(5), 261-270.

Walsh-Sukys, M., Reitenbach, A., Hudson-Barr, D., \& DePompei, P. (2001). Reducing light and sound in the neonatal intensive care unit: An evaluation of patient safety, staff satisfaction and costs. Journal of Perinatology, 21(4), 230-235.

Ward, A. C., Liker, J. K., Cristiano, J. J., \& Sobek II, D. K. (1995). The second Toyota paradox: How delaying decisions can make better cars faster. Sloan Management Review, 36(3), 43-61.

White, R. (2007). Flooring choices for newborn ICUs. Journal of Perinatology, 27(S2), S29-S31.

White, R. (2011). The newborn intensive care unit environment of care: How we got here, where we're headed, and why. Seminars in Perinatology, 35(1), 2-7.

White, R., Browne, J., Cicco, R., Erickson, D., Graven, S., Gregory, S., . . . King, J. (2007). Recommended standards for newborn ICU design. Journal of Perinatology, 19(8), Part II, S2-S12.

White, R., Smith, J., \& Harrell, J. (2012). New recommended standards for NICU design. Paper presented at the The Gravens Conference: The Physical and Developmental Environment of the High Risk Infant, January 26-28, Clearwater Beach, FL.

Womack, J. P., \& Jones, D. T. (2003). Lean thinking. New York, NY: Free Press.

Womack, J. P., Jones, D. T., \& Roos, D. (1990). The machine that changed the world. New York, NY: Free Press.

Zidel, T. G. (2006). A Lean guide to transforming healthcare: How to implement Lean principles in hospitals, medical offices, clinics and other healthcare organizations. Milwaukee, WI: ASQ Quality Press.

\section{Implications for Practice}

- The principals of Target Value Design are critical to responsible professional practice. By embracing the activities described in this article, designers will enhance the efficiency and effectiveness of healthcare environments.

- The design process for NICUs will benefit particularly from integrated project teams because of the evolution that is occurring relative to open-bay versus private room unit configurations.

- The collaboration of all design team members is necessary to make decisions regarding the implications of these two approaches. 
Copyright of Health Environments Research \& Design Journal (HERD) is the property of Vendome Group LLC and its content may not be copied or emailed to multiple sites or posted to a listserv without the copyright holder's express written permission. However, users may print, download, or email articles for individual use. 